medRxiv preprint doi: https://doi.org/10.1101/2022.01.18.22269408; this version posted January 21, 2022. The copyright holder for this preprint (which was not certified by peer review) is the author/funder, who has granted medRxiv a license to display the preprint in perpetuity.

It is made available under a CC-BY-NC-ND 4.0 International license .

\title{
The impact of recurrent rapid test strategies on the effectiveness of at-home antiviral treatments for SARS-CoV-2
}

\author{
Authors: Tigist F Menkir ${ }^{1,2}$ and Christl A Donnelly ${ }^{2,3}$ \\ ${ }^{1}$ Center for Communicable Disease Dynamics, Department of Epidemiology, Harvard T.H. Chan \\ School of Public Health, Harvard University, Boston, Massachusetts, USA \\ ${ }^{2}$ Department of Statistics, Oxford University, Oxford, UK \\ ${ }^{3} \mathrm{MRC}$ Centre for Global Infectious Disease Analysis, Department of Infectious Disease \\ Epidemiology, Imperial College London, London, UK
}

\begin{abstract}
:
As has been consistently demonstrated, rapid tests administered at regular intervals can offer significant benefits to both individuals and their communities at large by helping identify whether an individual is infected and potentially infectious. An additional advantage to the individual is that positive tests may be provided sufficiently early enough during their infection that treatment with antiviral treatments can effectively inhibit development of severe disease, particularly when PCR uptake is limited and delays to receipt of results are substantial. Here, we provide a quantitative illustration of the extent to which rapid tests administered at various intervals can deliver benefits accrued from the novel Pfizer treatment (Paxlovid). We find that strategies for which tests are administered more routinely, i.e. every other day or once every three days, are associated with greater reductions in the risk of hospitalization and correspondingly, higher proportions of the infected population benefiting from treatment. We further observed that reduced positive-test-to-treatment delays and increased treatment coverage have a critical influence on average treatment benefits, signaling the importance of treatment access.
\end{abstract}

Main text:

Rapid tests for SARS-CoV-2 have been shown to help identify individuals who may be infectious. $^{1-3}$ Their newfound use, particularly among those prone to severe disease, is identifying infections early enough that they can be effectively treated with antiviral treatments, including the Pfizer candidate PF-07321332 (Paxlovid) ${ }^{4,5}$, which necessitates early use to lower the risk of hospitalization. Here, we demonstrate that testing rates, as well as treatment coverage rates and positive-test-to-treatment delays, shape the impacts of such test-and-treat policies.

Many have promoted rapid testing to identify infections when antivirals are still helpful ${ }^{6-8}$, so there is a need to quantify the extent to which frequent rapid testing can enable patients to benefit from the treatment. We thus build on prior studies which characterized the ability of rapid testing strategies to identify presymptomatic and/or asymptomatic patients or to reduce transmission. ${ }^{9-12}$ 
medRxiv preprint doi: https://doi.org/10.1101/2022.01.18.22269408; this version posted January 21, 2022. The copyright holder for this preprint (which was not certified by peer review) is the author/funder, who has granted medRxiv a license to display the preprint in perpetuity. It is made available under a CC-BY-NC-ND 4.0 International license .

To evaluate the benefits of recurrent rapid testing at different rates on treatment effects, we used LFT-associated positivity data from a Hellewell et al. analysis ${ }^{9}$ and estimated hospitalization risks at three and five days following the onset of symptoms from the latest summary of the Phase 2/3 EPIC-HR trial findings. ${ }^{4}$ Specifically, for each rapid testing strategy (once every other day, once every three days, once a week, and once every two weeks) we estimated test-positivity-probability-weighted risk ratios (RRs) of hospitalization as a function of time since infection, the proportion of the infected population who would be offered the treatment, and the proportion of the infected population who would take it sufficiently early to benefit from treatment. Finally, we explored the sensitivity of our findings to assumed treatment efficacy trends, and two measures of access: treatment uptake or coverage and the delay from testing positive to treatment.

As expected, we found that when tests are administered more frequently, the benefits associated with Paxlovid initiation increase dramatically, such that treatment substantially reduces the risk of hospitalization (Figure 1A). While the median RR associated with the every other day strategy is $0.17(95 \% \mathrm{Cl}: 0.12,0.28)$, the median RR associated with the once every two weeks strategy is $0.77(95 \% \mathrm{Cl}: 0.69,0.84)$, with a dramatic increase in median RRs from the two 'higher frequency' testing regimes to the less frequent testing alternatives (Figure 1A). Correspondingly, we see a pronounced increase in the proportion of the infected population benefiting from treatment as testing frequency increases, ranging from $25.7 \%$ (95\% $\mathrm{Cl}: 18.2$, $33.9)$ to $92.0 \%(95 \% \mathrm{Cl}: 79.8,97.9)$ (Figure 1B). The estimates of proportion given the treatment and proportion actually deriving some benefit from it indicate that nearly everyone who tests positive and thus takes treatment receives some benefit. This arises because, in the estimated Hellewell et al. positivity curves ${ }^{9}$, nearly all positive tests occur within two weeks of infection. Consequently, under our base case scenario, where drug-associated benefits extend to seven days since symptom onset (which corresponds to twelve days since infection assuming an incubation period of five days), almost all individuals who test positive are captured within this drug efficacy window. Finally, we note that the magnitude of weighted RRs and ranking across strategies are negligibly sensitive to our assumed treatment efficacy scenario (Figure 2).

We found that the benefits of treatment depend on both treatment coverage and the delay from testing positive to treatment (Figures 3 and 4). To achieve RRs within the range of what we observed with full coverage, zero delays and testing every other day, treatment coverage of at least $70 \%$ would require positive-test-to-treatment delays of no more than two days. With less frequent testing, treatment coverage and positive-test-to-treatment delays are critical, with smaller RRs achieved only through nearly full coverage and delays of no more than two days.

Based on the hospitalization risks at the two treatment initiation times considered in the Phase 2/3 EPIC-HR trial, we fitted RRs and assumed a linear decline in efficacy to estimate the treatment efficacy levels associated with Paxlovid treatment across a range of days since symptom onset. To vary these assumptions, we considered trends that could capture two different time windows of efficacy beyond the range considered in the trial, and found little to no changes in our estimated RRs. We further note that while non-linear trends may marginally alter 
the magnitude of our expected RRs, with RRs inflated towards 1 if we assume a curvilinear decline consistent with a shorter efficacy window, they are unlikely to change the observed relative magnitude across strategies. Secondly, the positivity data from the Hellewell et al. analysis assumed an "LFT-like" CT threshold of $28 .{ }^{9}$ If a lower CT threshold were used, we would expect the estimated RRs of hospitalization to increase and the corresponding proportion benefiting from the treatment to decrease, with the converse holding true for a higher assumed CT threshold. However, the ordering of RRs across strategies would once again persist. Patient data were collected in early 2020 , such that time-specific positivity estimates were obtained from wild-type infections, with trends that could differ from the prevailing variant. In contrast, hospitalization risks were estimated using data from July 2021 and thus likely were recorded on largely delta-infected patients. ${ }^{5}$ Thus, it is important to update our results specific to the latest variant and among vaccinated populations ${ }^{5}$, once new data become available.

In sum, we characterized how rapid testing may facilitate treatment benefits, with the most frequent testing yielding the best results. Treatment access matters: high coverage and short delays are necessary to achieve large benefits. Spatially-refined testing strategies might support disadvantaged communities where vulnerabilities to severe disease and barriers to testing and treatment are most concentrated. Finally, frequent testing potentially reduces costs, particularly in high-prevalence settings, dramatically reducing hospitalizations, which may outweigh the costs of testing and treatment distribution. 
medRxiv preprint doi: https://doi.org/10.1101/2022.01.18.22269408; this version posted January 21, 2022. The copyright holder for this preprint (which was not certified by peer review) is the author/funder, who has granted medRxiv a license to display the preprint in perpetuity.

It is made available under a CC-BY-NC-ND 4.0 International license .

\section{References}

1. Mina MJ, Parker R, Larremore DB. Rethinking Covid-19 Test Sensitivity - A Strategy for Containment. N Engl J Med 2020;383(22):e120.

2. Petersen I, Crozier A, Buchan I, Mina MJ, Bartlett JW. Recalibrating SARS-CoV-2 Antigen Rapid Lateral Flow Test Relative Sensitivity from Validation Studies to Absolute Sensitivity for Indicating Individuals Shedding Transmissible Virus. CLEP 2021;Volume 13:935-40.

3. Lee LYW, Rozmanowski S, Pang M, et al. Severe Acute Respiratory Syndrome Coronavirus 2 (SARS-CoV-2) Infectivity by Viral Load, S Gene Variants and Demographic Factors, and the Utility of Lateral Flow Devices to Prevent Transmission. Clinical Infectious Diseases 2021; ciab421.

4. Pfizer: Media relations. Pfizer Announces Additional Phase 2/3 Study Results Confirming Robust Efficacy of Novel COVID-19 Oral Antiviral Treatment Candidate in Reducing Risk of Hospitalization or Death [Internet]. 2021. Available from:

https://www.pfizer.com/news/press-release/press-release-detail/pfizer-announces-additional -phase-23-study-results

5. Pfizer. EPIC-HR: Study of Oral PF-07321332/Ritonavir Compared With Placebo in Nonhospitalized High Risk Adults With COVID-19 [Internet]. 2021;Available from: https://clinicaltrials.gov/ct2/show/NCT04960202

6. Wroe EB, Seung KJ, Baker BK, Farmer PE. Test and treat: a missing link in the global fight against COVID-19. The Lancet Global Health 2021;S2214109X21005684.

7. Walsh B. New COVID pill shows the need for widescale testing [Internet]. Axios. 2021;Available from:

https://www.axios.com/pfizer-coronavirus-pill-rapid-test-39ebdc5e-7c96-4ed3-a1fc-ac7273a 30050.html

8. Anthes E. As Antiviral Pills Arrive, Can Testing Keep Up? [Internet]. The New York Times. 2021;Available from: https://www.nytimes.com/2021/11/29/health/covid-pill.html

9. Hellewell J, Russell TW, The SAFER Investigators and Field Study Team, et al. Estimating the effectiveness of routine asymptomatic PCR testing at different frequencies for the detection of SARS-CoV-2 infections. BMC Med 2021;19(106).

10. Larremore $D B$, Wilder $B$, Lester $E$, et al. Test sensitivity is secondary to frequency and turnaround time for COVID-19 screening. Sci Adv 2021;7(1):eabd5393.

11. Holmdahl I, Kahn R, Hay JA, Buckee CO, Mina MJ. Estimation of Transmission of COVID-19 in Simulated Nursing Homes With Frequent Testing and Immunity-Based Staffing. JAMA Netw Open 2021;4(5):e2110071.

12. Kiang MV, Chin ET, Huynh BQ, et al. Routine asymptomatic testing strategies for airline travel during the COVID-19 pandemic: a simulation study. The Lancet Infectious Diseases 2021;21(7):929-38. 
medRxiv preprint doi: https://doi.org/10.1101/2022.01.18.22269408; this version posted January 21, 2022. The copyright holder for this preprint (which was not certified by peer review) is the author/funder, who has granted medRxiv a license to display the preprint in perpetuity.

\section{It is made available under a CC-BY-NC-ND 4.0 International license .}

Figures

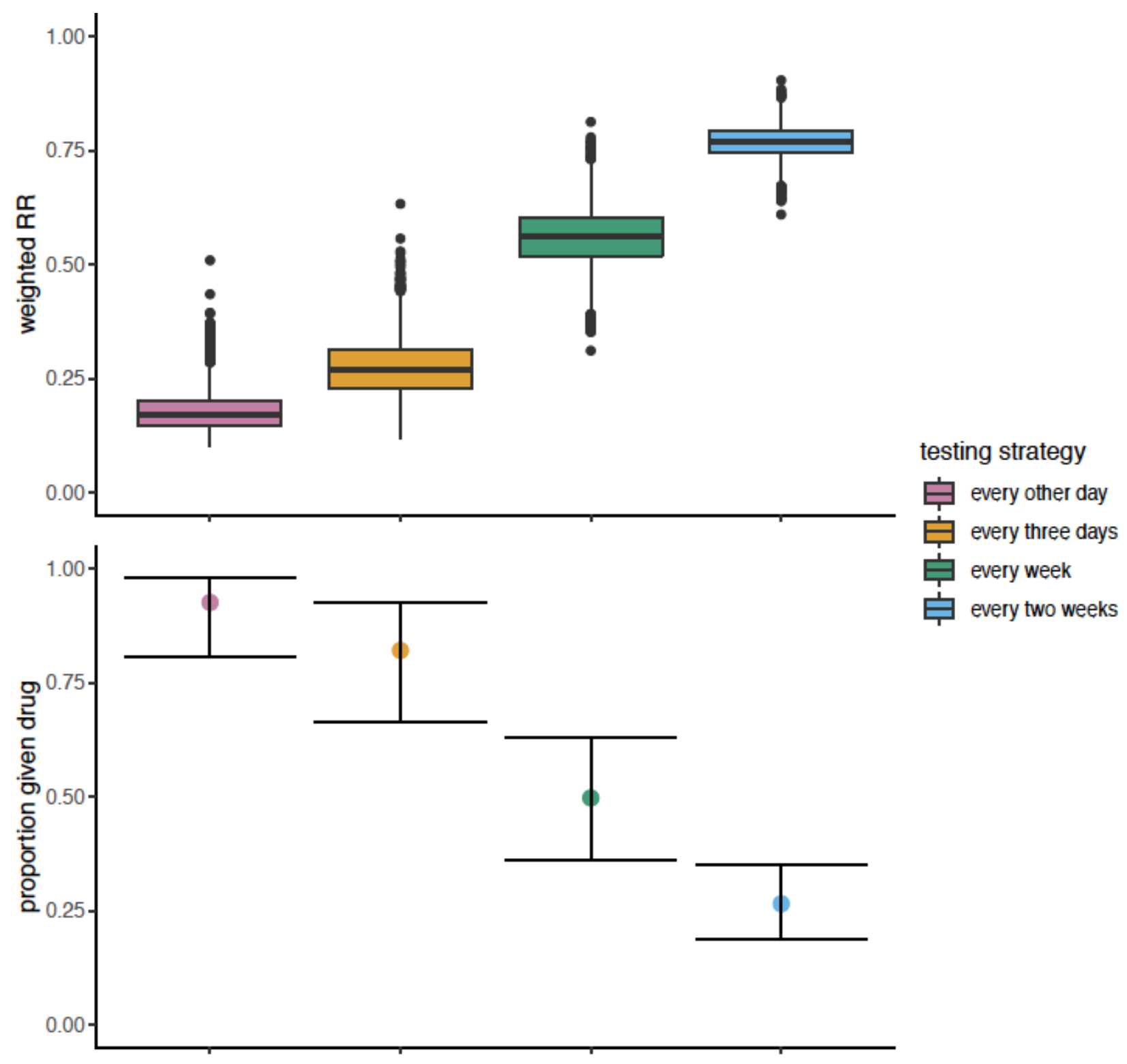

Figure 1. (A) Distribution of estimated test-positivity-probability-weighted risk ratios (RRs) by testing strategy: every other day, every three days, every week, and every two weeks (B) Estimated proportions given treatment by testing strategy. In all cases no positive-test-to-treatment delay was assumed. 
medRxiv preprint doi: https://doi.org/10.1101/2022.01.18.22269408; this version posted January 21, 2022. The copyright holder for this preprint (which was not certified by peer review) is the author/funder, who has granted medRxiv a license to display the preprint in perpetuity. It is made available under a CC-BY-NC-ND 4.0 International license.

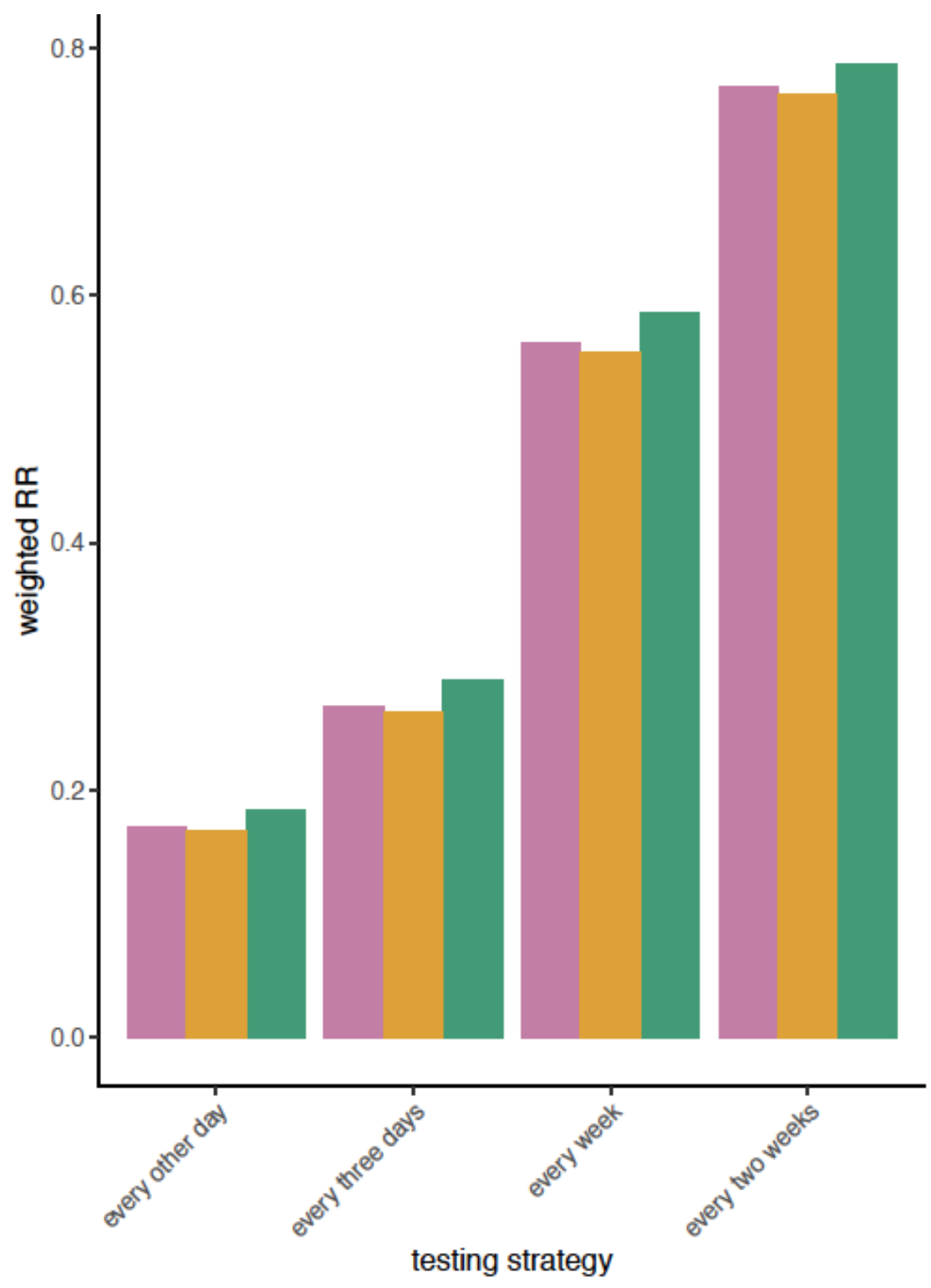

scenario

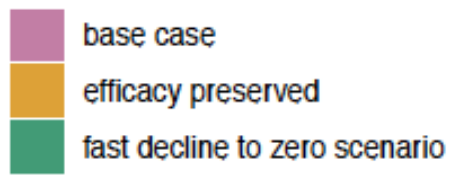

Figure 2. Median estimated test-positivity-probability-weighted risk ratios (RRs) by assumed treatment efficacy scenario (base case scenario, scenario with preserved efficacy following five days after symptom onset, and scenario with efficacy dropping to zero following days after symptom onset) across testing strategies: every other day, every three days, every week, and every two weeks. In all cases no positive-test-to-treatment delay was assumed. 
medRxiv preprint doi: https://doi.org/10.1101/2022.01.18.22269408; this version posted January 21, 2022. The copyright holder for this preprint (which was not certified by peer review) is the author/funder, who has granted medRxiv a license to display the preprint in perpetuity.

It is made available under a CC-BY-NC-ND 4.0 International license .
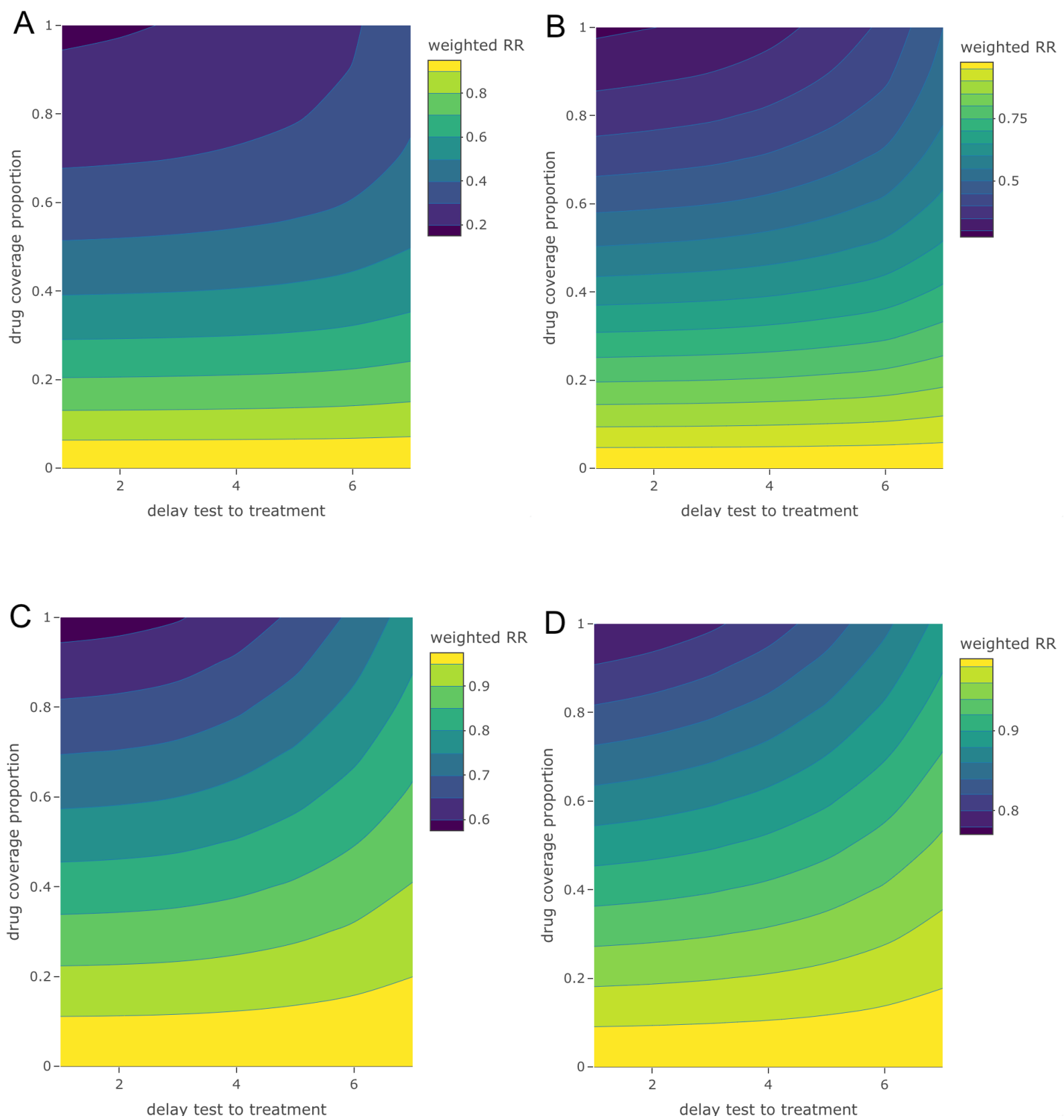

Figure 3. Sensitivity of estimated test-positivity-probability-weighted risk ratios (RRs) to positive-test-to-treatment delays (x-axis) up to seven days and treatment coverage proportions (y-axis) up to full coverage, by testing strategy (A-every other day, B- every three days, C-every week, D-every two weeks). Darker colors indicate reduced weighted RRs, i.e. greater treatment-associated reductions in hospitalization in risks. 
A

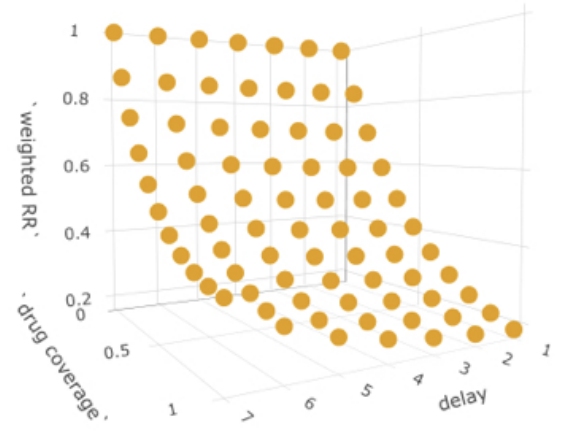

C

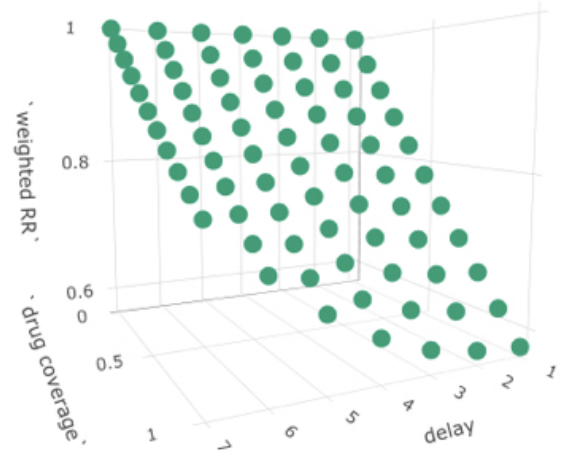

$\mathrm{B}$
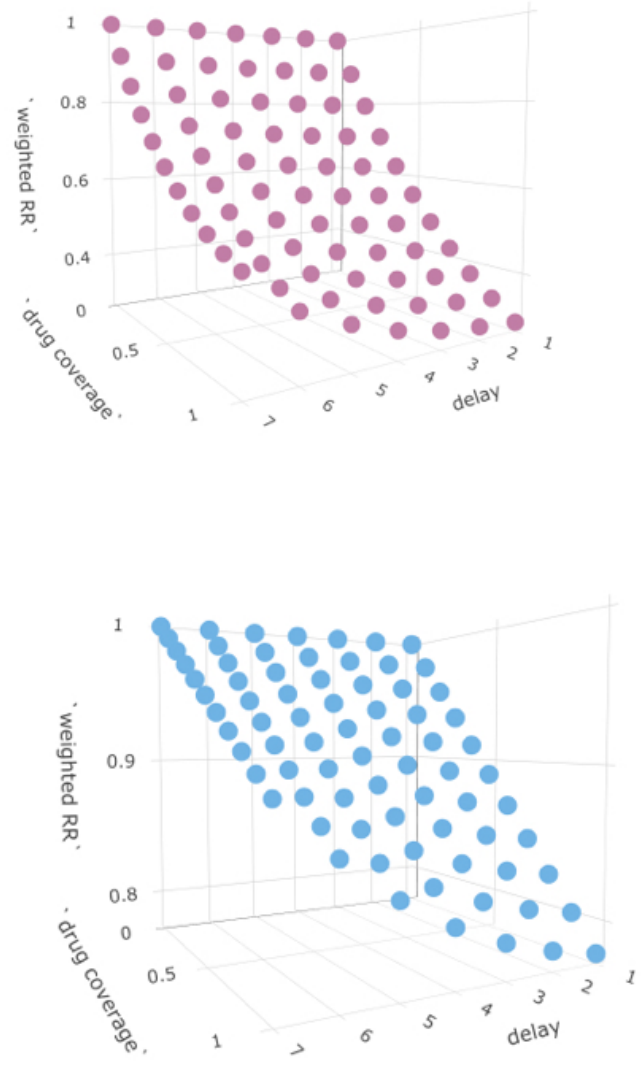

Figure 4. Alternative representation of Figure 3, reporting the combined impacts of positive-test-to-treatment delays ( $\mathrm{y}$-axis) and treatment coverage proportions (x-axis) on test-positivity-probability-weighted risk ratios (RRs) (z-axis), by testing strategy (A-every other day, B- every three days, C-every week, D-every two weeks). 